\title{
A new assay based on terminal restriction fragment length polymorphism of homocitrate synthase gene fragments for Candida species identification
}

\author{
Kasjan Szemiako $^{1}$ • Anna Śledzińska ${ }^{2} \cdot$ Beata Krawczyk $^{1}$
}

Received: 7 November 2016 / Revised: 21 February 2017 / Accepted: 17 March 2017 / Published online: 27 March 2017

(C) The Author(s) 2017. This article is published with open access at Springerlink.com

\begin{abstract}
Candida sp. have been responsible for an increasing number of infections, especially in patients with immunodeficiency. Species-specific differentiation of Candida sp. is difficult in routine diagnosis. This identification can have a highly significant association in therapy and prophylaxis. This work has shown a new application of the terminal restriction fragment length polymorphism ( $t-$ RFLP) method in the molecular identification of six species of Candida, which are the most common causes of fungal infections. Specific for fungi homocitrate synthase gene was chosen as a molecular target for amplification. The use of three restriction enzymes, $D r a \mathrm{I}, R s a \mathrm{I}$, and $B g l I I$, for amplicon digestion can generate speciesspecific fluorescence labeled DNA fragment profiles, which can be used to determine the diagnostic algorithm. The designed method can be a cost-efficient high-throughput molecular technique for the identification of six clinically important Candida species.
\end{abstract}

Keywords Candida $\cdot$ t-RFLP · PCR · Homocitrate synthase gene $\cdot$ Molecular diagnostic

\section{Introduction}

Fungal infections of the Candida sp. etiology are a serious clinical problem. The mortality of candidemia episodes

Communicated by: Agnieszka Szalewska-Palasz

Beata Krawczyk

beakrawc@pg.gda.pl

1 Department of Molecular Biotechnology and Microbiology, Faculty of Chemistry, Gdańsk University of Technology, Narutowicza 11/12, 80-233 Gdańsk, Poland

2 Department of Therapy Monitoring and Pharmacogenetics, Medical University of Gdańsk, Gdańsk, Poland exceeds $50 \%$. Furthermore, there are many factors which make this infection more and more dangerous, such as development of drug resistance, immunosuppressive therapies, diabetes, and increasing number of cancer incidence (LópezMartínez 2010). The treatment of infection varies depending on its etiological agents (Miceli et al. 2011). This is the main reason why rapid and accurate diagnosis is needed. Natural antibiotics resistance differs among Candida species, which makes it crucial to know which species are going to be dealt with (e.g., fluconazole resistance of C. glabrata and C. krusei, which is the first-line antifungal treatment) (Tortorano et al. 2004). Correct therapy based on fast and reliable diagnosis is essential to treat patients successfully and to decrease mortality.

Opportunistic fungal infections in immunocompromised hosts are caused mainly by Candida species, and the majority of such infections are due to C. albicans (Silveira-Gomes et al. 2011), which shares many phenotypic features with C. dubliniensis, and may, therefore, be misidentified in clinical microbiology laboratories. Species-specific differentiation of the two closely related yeasts, C. albicans and C. dubliniensis, is difficult in routine diagnosis. Reliable, routinely applicable methods for species-specific differentiation of C. albicans and C. dubliniensis appear to be of particular importance to better understand the epidemiology and virulence of C. dubliniensis (Hof et al. 2012). Candidemias caused by $C$. dubliniensis have been increasingly reported in recent years (Ahmad et al. 2012).

Methods for the identification of Candida sp. can be divided into conventional and molecular techniques. Conventional methods are based on the germ tube test, chlamydospore formation, and the fermentation or assimilation of sugars (Alam et al. 2014). There are also several chromogenic media for the isolation and identification of Candida species (Letscher-Bru et al. 2002). Colonies growing on these media have different 
morphology and color as a result from the cleavage of chromogenic substrates by species-specific enzymes (Bauters and Nelis 2002). However, the colors of colonies of one species may differ depending on the strain and may lead to misidentification (Ozcan et al. 2010). Methods for Candida identification can also be divided into non-DNA- and DNA-based techniques. In the group of non-DNA-based methods, there are such identification tests as serological [latex agglutination, enzyme-linked immunosorbent assay (ELISA), immunoblotting, dot immunoassay, liposomal immunoassay, and radioimmunoassay (RIA) (Ponton et al. 2002)] and spectroscopic methods (Manzoor et al. 2016). A very large and still fast developing group of methods are DNA-based techniques. They are mostly based on different types of polymerase chain reaction (PCR): microsatellite typing (Zane et al. 2002), multilocus sequence typing (MLST) (Odds 2010), randomly amplified polymorphic DNA (RAPD) (Melo et al. 1998), simplex PCR (Trtkova and Raclavsky 2006), multiplex PCR (Lau et al. 2008), nested PCR (Kanbe et al. 2002), real-time PCR (Fricke et al. 2010; Olchawa et al. 2013), and restriction fragment length polymorphism (RFLP) (de Llanos Frutos et al. 2004). The latter method as the terminal restriction fragment length polymorphism (t-RFLP) method is used for the genotyping and study of microbial diversity and microorganisms community structure in different environmental samples (Osborn et al. 2000; Schütte et al. 2008; Zhang et al. 2008; Waldron et al. 2009; Caretta and Brito 2011). This method is a modified classical PCR with a fluorescently labeled primer(s) and is linked to the digestion of amplicons with restriction enzyme(s). Only terminal fragments of PCR product containing fluorescent dye are visualized.

The aim of this study was to elaborate a method to differentiate six Candida species using the PCR t-RFLP technique based on a novel molecular target, the homocitrate synthase gene. The homocitrate synthase gene encodes an enzyme involved in the first reaction in the lysine biosynthesis pathway. The protein is characteristic for fungi and several Archaea and two isoforms are present for some Candida species. This gene is considered as a good molecular target for chemotherapy of disseminated fungal infections. It was the prerequisite for the selection of this gene as a novel molecular target for Candida species identification (Kur et al. 2010).

\section{Materials and methods}

\section{Candida strains}

In this study, the strains collection encompassed 75 clinical and six reference strains of Candida $\mathrm{sp}$. The reference strains were as follows: C. albicans ATCC 64544, C. krusei ATCC 6258, C. glabrata ATCC 2001, C. parapsilosis ATCC 22019, C. tropicalis ATCC 750, and C. dubliniensis ATCC MYA-646.
Clinical strains were collected from patients of Public Hospital No. 1 in Gdańsk, Poland and were identified according to the routine laboratory procedure. Strains were isolated from blood cultures (3), respiratory tract (28), urine (20), and genitourinary tract (from swabs) (24). In case of patients with suspected candidemia, blood was cultured using BacT/ALERT 3D (bioMérieux) for about 5 days. The species identification procedure involved subculture plates incubation on Sabouraud dextrose agar (SDA, bioMérieux), identification of isolated strains on chromogenic media for Candida (CHROMagar ${ }^{\circledR}$ Candida), and the biochemical panel VITEK® 2 .

\section{Culture and DNA isolation}

Yeasts were cultivated in Sabouraud media with chloramphenicol (Emapol, Poland) for $24 \mathrm{~h}$ at $37{ }^{\circ} \mathrm{C}$. The DNA isolation from the single colony was performed using the ExtractMe Purification Kit (Blirt DNA-Gdańsk, Poland), according to the manufacturer's recommended procedure. The DNA concentration was measured using a NanoDrop ND-100 spectrophotometer (Thermo Fisher Scientific, Wilmington, USA) and ranged from 10 to $60 \mathrm{ng}$ per microliter.

\section{PCR}

Based on the homocitrate synthase gene sequences available in the NCBI GenBank (C. albicans XM_708526, XM_708489, XM_707839, C. dubliniensis XM_002418342, XM_002417072,C. glabrata XM_447985, XM_448111, C. tropicalis XM_002547242, XM_002550342, and C. parapsilosis HE-605206-3, HE605203), oligonucleotide primers for PCR reaction were designed and their specificity was tested using, in both cases, the BLAST sequence tool (NCBI Blast). There were no sequences for $C$. krusei available and these sequences were obtained during this study (C. krusei KT_362370, KT_362371). $\mathrm{PCR}$ reaction was carried out using the standard protocol at a volume of $50 \mu \mathrm{L} 0.2 \mathrm{mM}$ of each dNTP (Blirt DNA-Gdańsk, Poland), $2 \mathrm{mM}$ of $\mathrm{MgCl}_{2}$ (Blirt DNA-Gdańsk, Poland), $4 \mu \mathrm{M}$ of each primer, the forward primer was labeled with fluorescein [5(6)FAM] at the $5^{\prime}$ end [LYSfor: 5'-5(6)FAMAGAGAAGGTGAACAATTTGC-3' and LYSrev: 5'-CCAA CAGTATCAGCAATACCAACTCT-3', Metabion, Germany], 1 U of $P f u$ Polymerase Hypernova (Blirt DNAGdańsk, Poland), and $1 \mu \mathrm{L}$ of fungal DNA. The reaction profile was as follows: $94{ }^{\circ} \mathrm{C}$ for 120 s initial denaturation, $94^{\circ} \mathrm{C}$ for $30 \mathrm{~s}, 59^{\circ} \mathrm{C}$ for $30 \mathrm{~s}$, and $72{ }^{\circ} \mathrm{C}$ for $30 \mathrm{~s}$ for 30 cycles, and then a final extension at $72{ }^{\circ} \mathrm{C}$ for $300 \mathrm{~s}$.

\section{Digestion of amplicons}

Restriction analysis of each amplicon was carried out with three endonucleases (Thermo Fisher Scientific, USA), RsaI, 
DraI, and $B g l I I$, as separate reactions. Restriction enzymes were chosen using the NEBcutter tool (New England Biolabs; http://tools.neb.com/NEBcutter/index.php3). They were optimized to obtain the most differentiation potential for distinguishing six Candida species using minimal types of enzymes. Digestion of amplicons was carried out in $20 \mu \mathrm{L}[15 \mu \mathrm{L}$ of PCR sample, $2 \mu \mathrm{L}$ of $10 \times$ reaction buffer (Thermo Fisher Scientific, USA), $0.5 \mu \mathrm{L}(2 \mathrm{U} / \mu \mathrm{L})$ of endonuclease, and $2.5 \mu \mathrm{L}$ of water] for $40 \mathrm{~min}$ at $37{ }^{\circ} \mathrm{C}$. Digested products were separated by electrophoresis in homemade $12 \%$ polyacrylamide gel. There was no ethidium bromide in gel; therefore, only fluorescence from fluoresceinlabeled primers was observed in UV light.

\section{Results and discussion}

The technique that forms the basis of the described method has become widely used in microbial community studies. Molecular methods are especially useful for culture-difficult and uncultivated microorganisms (Siqueira 2017). Microbial diversity studies involving the t-RFLP method investigate not only health and diseases influences (Jung et al. 2016), but also industry issues (Hedrich 2016). The most commonly used molecular targets are sequences within the ribosomal operon (Hayashi et al. 2014). In contrary to the references in this work, a novel application of the t-RFLP method is shown.

Table 1 Theoretical restriction fragments for Candida species. The numbers in bold represent the first restriction fragments from the $5^{\prime}$ end of the leading strand of polymerase chain reaction (PCR) products. These fragments contain fluorescently $5^{\prime}$ labeled primer and are visualized in electrophoresis. The other numbers represent the rest of the restriction fragments obtained after the digestion of PCR products (they are not visualized after electrophoresis). In some cases, there are two sets of restriction patterns for one species. This appears when the DNA sequences of enzyme isoschizomers gene polymorphism results in different recognition site positions

\begin{tabular}{|c|c|c|c|}
\hline \multirow[t]{2}{*}{ Species } & \multicolumn{3}{|c|}{ Endonuclease } \\
\hline & $B g l \mathrm{II}(\mathrm{bp})$ & RsaI (bp) & $\operatorname{DraI}(\mathrm{bp})$ \\
\hline C. albicans & $470^{*}$ & $420 * / 50$ & $161 * / 309$ \\
\hline C. dubliniensis & $\begin{array}{l}\mathbf{4 7 0} * \\
\mathbf{3 8 5}^{*} / 85\end{array}$ & $420 * / 50$ & $161 * / 309$ \\
\hline C. tropicalis & $\begin{array}{l}\mathbf{4 7 0} * \\
\mathbf{3 8 5}^{*} / 85\end{array}$ & $255 * / 164 / 51$ & $161 / 309$ \\
\hline C. glabrata & $470 *$ & $\mathbf{2 5 5} * / 193 / 22$ & $470^{*}$ \\
\hline C. parapsilosis & $\begin{array}{l}\text { 470* } \\
171 * / 299\end{array}$ & $420 * / 50$ & $470^{*}$ \\
\hline C. krusei & $470 *$ & $255 * / 164 / 51$ & $\mathbf{1 6 1} * / 309$ \\
\hline
\end{tabular}

*Fragment labeled with fluorescence as a visible band on electrophoretic gel
The selection of specific molecular targets other than ribosomal DNA and designing the method for species identification shows the new potential of the t-RFLP method.

In this study, we apply the t-RFLP method for the identification of the six medically important Candida species using the universal primers for homocitrate synthase gene fragments. The length of PCR products for all Candida tested was $470 \mathrm{bp}$. It was established in silico using the NCBI Primer Blast tool. A set of three restriction endonucleases (RsaI, DraI, and BglII) for differentiation of the investigated Candida species was chosen. Optimization of the number and kind of enzymes was carried out based on the NEBCutter tool. Two genes, LYS21 and LYS22, encoding isoforms of homocitrate synthase, are present and, for each copy, we can get a different pattern of digestion or not. The results of theoretical restriction patterns are presented in Table 1.

We have shown discriminatory power for these restriction enzymes to distinguish the particular Candida species (Figs. 1 and 2). They have the potential for differentiation of six clinically important Candida species. Additionally, the digestion step can be modified for specific needs. Depending on how many and which species must be identified, the optimal steps of digestion by different enzymes and their order may be chosen. For example, the identification of $C$. parapsilosis sensu lato may be realized with only one $B g l I I$ enzyme. In the case of C. albicans and C. dubliniensis, two RsaI and DraI enzymes can be used for identification. The need to use all three restriction enzymes is only applicable when all six of the investigated Candida species may be expected in a sample. The presence of a 470-bp band indicates that there is a lack of amplicon digestion. An appearance of another fragment in

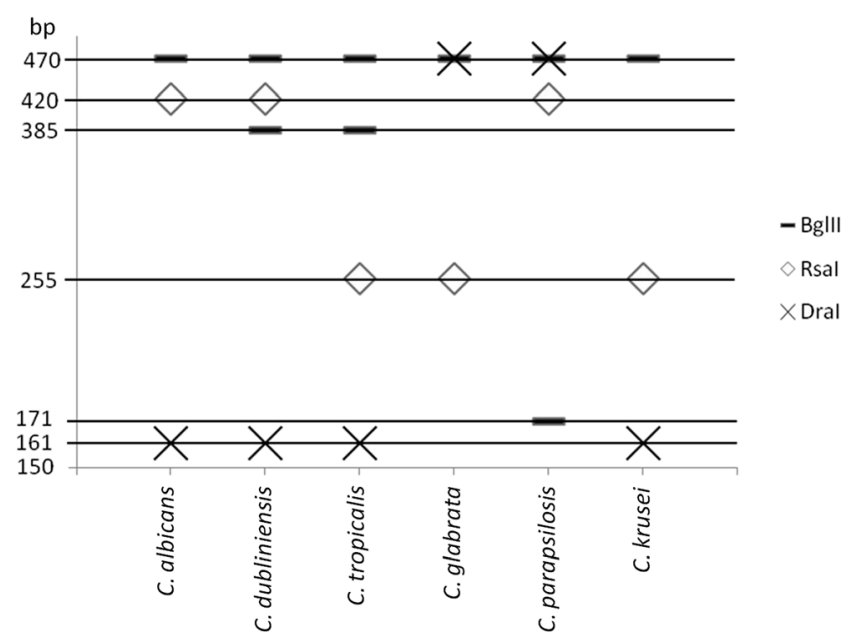

Fig. 1 Theoretical restriction patterns after electrophoresis for each species. RsaI, BglII, and DraI are the restriction enzymes. Each icon described in the legend represents one restriction enzyme, for which restriction products that should appear in gel after electrophoresis are visualized. The length of restriction products with fluorescently labeled primers is represented by the $y$-axis 


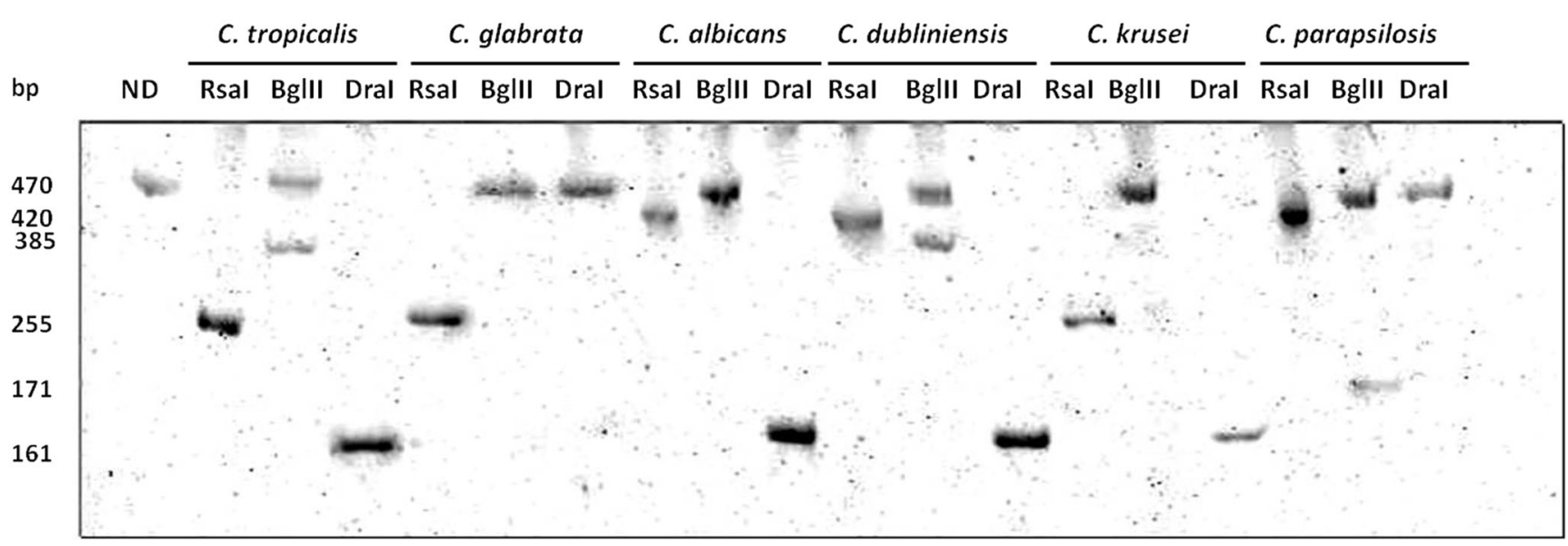

Fig. 2 Electropherogram of digestion products obtained for the six reference Candida strains. Electrophoresis was carried out in $12 \%$ polyacrylamide gel for $3 \mathrm{~h}(8 \mathrm{~V} / \mathrm{cm})$. There was no dye in the gel.
Visualization of DNA fragments was carried out in UV light. $N D$ polymerase chain reaction (PCR) product without digestion; RsaI, $B g l \mathrm{II}$, and $\mathrm{DraI}$ are the patterns of digestion for restriction enzymes the presence of a 470-bp band for the particular enzyme indicates that the second copy of this gene has a restriction site.

The established diagnostic algorithm for reference strains was confirmed with clinical strains (Fig. 3). All clinical strains were identified correctly compared to results obtained using CHROMagar. Clinical strains identified by the t-RFLP method and clinical sources are presented in Table 2. However, very often, phenotyping methods like CHROMagar create problems with determining the color and giving an accurate identification, so choosing the appropriate therapy is impossible. All digestion reactions must be carried out in separate tubes because simultaneous digestion with three endonucleases in one reaction results in obtaining only the shortest product, which does not identify the species. However, different restriction patterns allows to mix reaction mixtures for all three nucleases after digestion and separate such mixtures using electrophoresis (C. albicans three bands 470, 420, and 161; C. dubliniensis four bands 470, 420, 385, and 161;
C. tropicalis three bands 470,385 , and $161 ;$ C. glabrata two bands 470 and 255; $C$. parapsilosis three bands 470, 420, and 171; and C. krusei three bands 470, 255, and 161) (Fig. 1). Digested products may also be separated by electrophoresis in 3-4\% high-resolution agarose gel (agarose HiRes grade, Bioline) for $90 \mathrm{~min}(7 \mathrm{~V} / \mathrm{cm})$, but the detection sensitivity decreases and, therefore, more products of the digestion reaction should be applied.

In this study, pure yeasts cultures growing on plate agar were used. They were isolated from clinical samples. This fact confirms that the described method is universal for the correct identification of different strains of Candida and allows it to be used as a diagnostic method in clinical laboratories.

Due to the specificity of primers in the PCR, simple detection method, and analyzing of the digestion products profile, the t-RFLP method can probably be used for the identification of Candida sp. from biological samples. However, further validation is needed, because the sensitivity of PCR may

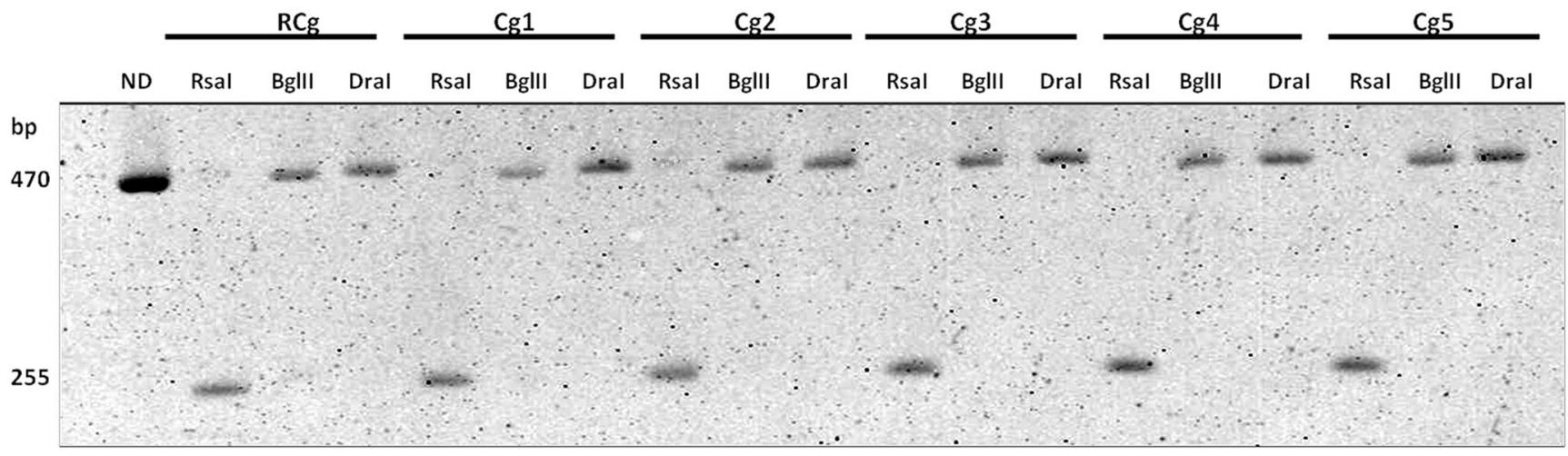

Fig. 3 Representative electropherogram obtained for clinical strains of Candida glabrata using the terminal restriction fragment length polymorphism (t-RFLP) PCR method. Electrophoresis was carried out in $12 \%$ polyacrylamide gel for $3 \mathrm{~h}(8 \mathrm{~V} / \mathrm{cm})$. There was no dye in the gel.
Visualization of DNA fragments was carried out in UV light. ND PCR product without digestion of restriction enzyme(s); $R C g C$. glabrata ATCC 2001 reference strain; $C g 1, C g 2, C g 3, C g 4, C g 5$ C. glabrata clinical strains; RsaI, BglII, and DraI are the restriction enzymes 
Table 2 Clinical strains identified using the terminal restriction fragment length polymorphism (t-RFLP) method

\begin{tabular}{lllll}
\hline Species & \multicolumn{2}{l}{ Clinical sample } & & \\
\cline { 2 - 5 } & $\begin{array}{l}\text { Blood cultures } \\
(n=3)\end{array}$ & $\begin{array}{l}\text { Respiratory tract } \\
(n=28)\end{array}$ & Urine $(n=20)$ & $\begin{array}{l}\text { Genitourinary tract (swabs) } \\
(n=24)\end{array}$ \\
\hline C. glabrata & 1 & 6 & 4 & 6 \\
C. krusei & 2 & 6 & 5 & 5 \\
C. parapsilosis & - & 4 & - & 4 \\
C. albicans & - & 7 & 7 & 7 \\
C. tropicalis & - & 5 & 4 & 2 \\
\hline
\end{tabular}

decrease as a result of the inhibitors, e.g., in blood or sputum (Al-Soud and Rådström 2001; Amicosante et al. 1995).

The sensitivity of the t-RFLP method is also dependent on the restriction products detection method. Capillary electrophoresis is more sensitive than polyacrylamide gel electrophoresis and a smaller amount of digested PCR products is needed. It is also more precise and may be a good solution for routine laboratory diagnostics because it can be automated (Fawley et al. 2015).

\section{Conclusions}

In this study, a novel application for the terminal restriction fragment length polymorphism (t-RFLP) method was developed. The results of this research lead to two main innovative issues: new molecular target for the identification of Candida species and showing the potential of the t-RFLP method for diagnostic purposes. This method was successfully applied to bacterial and yeast community investigations in different environments or microbiota analysis. In this study, the genotyping potential of the t-RFLP method has been extended to the identification of Candida species. The results of this study yield a novel tool for clinical diagnostics and highlights a new path for the development of the t-RFLP method. The designed method can be a cost-efficient, high-throughput molecular technique able to determine specific and simple restriction patterns for the identification of six clinically important Candida species.

Acknowledgments No funding was received for this work.

Authors' contributions KS carried out many of the experiments as a $\mathrm{PhD}$ student, participated in field work, and drafted the manuscript; AŚ collected strains, performed the microbial examination of the Candida sp., participated in the interpretation of results, and was a contributor in the final corrections of the manuscript; BK was the supervisor and chief designer of the project, participated in the conception, design, and supervision of the experiments, and in the drafting and revision of the manuscript.

All authors read and approved the final manuscript.

\section{Compliance with ethical standards}

Conflict of interest The authors declare that they have no competing interests.

Open Access This article is distributed under the terms of the Creative Commons Attribution 4.0 International License (http:// creativecommons.org/licenses/by/4.0/), which permits unrestricted use, distribution, and reproduction in any medium, provided you give appropriate credit to the original author(s) and the source, provide a link to the Creative Commons license, and indicate if changes were made.

\section{References}

Ahmad S, Khan Z, Asadzadeh M, Theyyathel A, Chandy R (2012) Performance comparison of phenotypic and molecular methods for detection and differentiation of Candida albicans and Candida dubliniensis. BMC Infect Dis 12:230. doi:10. 1186/1471-2334-12-230

Al-Soud WA, Rådström P (2001) Purification and characterization of PCR-inhibitory components in blood cells. J Clin Microbiol 39(2): 485-493

Alam MZ, Alam Q, Jiman-Fatani A, Kamal MA, Abuzenadah AM, Chaudhary AG, Akram M, Haque A (2014) Candida identification: a journey from conventional to molecular methods in medical mycology. World J Microbiol Biotechnol 30:1437-1451. doi:10.1007/ s11274-013-1574-z

Amicosante M, Richeldi L, Trenti G, Paone G, Campa M, Bisetti A, Saltini C (1995) Inactivation of polymerase inhibitors for Mycobacterium tuberculosis DNA amplification in sputum by using capture resin. J Clin Microbiol 33(3):629-630

Bauters TG, Nelis HJ (2002) Comparison of chromogenic and fluorogenic membrane filtration methods for detection of four Candida species. J Clin Microbiol 40:1838-1839. doi:10.1128/ JCM.40.5.1838-1839.2002

Caretta CA, Brito EMS (2011) In silico restriction analysis for identifying microbial communities in T-RFLP fingerprints. J Comput Interdisci Sci 2:123-129. doi:10.6062/jcis.2011.02.02.0039

de Llanos Frutos R, Fernández-Espinar MT, Querol A (2004) Identification of species of the genus Candida by analysis of the 5.8S rRNA gene and the two ribosomal internal transcribed spacers. Antonie Van Leeuwenhoek 85:175-185. doi:10.1023/B:ANTO. 0000020154.56649.0f

Fawley WN, Knetsch CW, MacCannell DR, Harmanus C, Du T, Mulvey MR, Paulick A, Anderson L, Kuijper EJ, Wilcox MH (2015) Development and validation of an internationally-standardized, 
high-resolution capillary gel-based electrophoresis PCR-ribotyping protocol for Clostridium difficile. PLoS One 10(2):e0118150. doi: 10.1371/journal.pone. 0118150

Fricke S, Fricke C, Schimmelpfennig C, Oelkrug C, Schönfelder U, Blatz R, Zilch C, Faber S, Hilger N, Ruhnke M, Rodloff AC (2010) A real-time PCR assay for the differentiation of Candida species. J Appl Microbiol 109:1150-1158. doi:10. 1111/j.1365-2672.2010.04736.x

Hayashi Y, Saito T, Ohshima T, Nakagawa Y, Arita T, Yashima A, Makino T, Konnai R, Gomi K, Arai T, Maeda N (2014) Terminal RFLP analysis to determine the oral microbiota with hyposalivation. Arch Microbiol 196(7):489-496. doi:10.1007/s00203-014-0987-x

Hedrich S, Guézennec AG, Charron M, Schippers A, Joulian C (2016) Quantitative monitoring of microbial species during bioleaching of a copper concentrate. Front Microbiol 7:2044. doi:10.3389/fmicb. 2016.02044

Hof H, Eigner U, Maier T, Staib P (2012) Differentiation of Candida dubliniensis from Candida albicans by means of MALDI-TOF mass spectrometry. Clin Lab 58:927-931

Jung JW, Choi JC, Shin JW, Kim JY, Park IW, Choi BW, Park HW, Cho SH, Kim K, Kang HR (2016) Lung microbiome analysis in steroidnaïve asthma patients by using whole sputum. Tuberc Respir Dis (Seoul) 79(3):165-178. doi:10.4046/trd.2016.79.3.165

Kanbe T, Horii T, Arishima T, Ozeki M, Kikuchi A (2002) PCR-based identification of pathogenic Candida species using primer mixes specific to Candida DNA topoisomerase II genes. Yeast 19:973-989

Kur K, Gabriel I, Morschhäuser J, Barchiesi F, Spreghini E, Milewski S (2010) Disruption of homocitrate synthase genes in Candida albicans affects growth but not virulence. Mycopathologia 170: 397-402

Lau A, Sorrell TC, Chen S, Stanley K, Iredell J, Halliday C (2008) Multiplex tandem PCR: a novel platform for rapid detection and identification of fungal pathogens from blood culture specimens. J Clin Microbiol 46:3021-3027. doi:10.1128/JCM.00689-08

Letscher-Bru V, Meyer MH, Galoisy AC, Waller J, Candolfi E (2002) Prospective evaluation of the new chromogenic medium Candida ID, in comparison with Candiselect, for isolation of molds and isolation and presumptive identification of yeast species. J Clin Microbiol 40:1508-1510

López-Martínez R (2010) Candidosis, a new challenge. Clin Dermatol 28:178-184. doi:10.1016/j.clindermatol.2009.12.014

Manzoor S, Ugena L, Tornero-Lopéz J, Martín H, Molina M, Camacho JJ, Cáceres JO (2016) Laser induced breakdown spectroscopy for the discrimination of Candida strains. Talanta 155:101-106. doi:10. 1016/j.talanta.2016.04.030

Melo AS, de Almeida LP, Colombo AL, Briones MR (1998) Evolutionary distances and identification of Candida species in clinical isolates by randomly amplified polymorphic DNA (RAPD). Mycopathologia 142:57-66. doi:10.1023/a:1006998325716
Miceli MH, Díaz JA, Lee SA (2011) Emerging opportunistic yeast infections. Lancet Infect Dis 11:142-151. doi:10.1016/S14733099(10)70218-8

Odds FC (2010) Molecular phylogenetics and epidemiology of Candida albicans. Future Microbiol 5:67-79. doi:10.2217/fmb.09.113

Olchawa A, Krawczyk B, Brillowska-Dabrowska A (2013) New PCR test for detection of Candida glabrata based on the molecular target chosen by the RAPD technique. Pol J Microbiol 62:81-84

Osborn AM, Moore ER, Timmis KN (2000) An evaluation of terminalrestriction fragment length polymorphism (T-RFLP) analysis for the study of microbial community structure and dynamics. Environ Microbiol 2:39-50

Ozcan K, Ilkit M, Ates A, Turac-Bicer A, Demirhindi H (2010) Performance of Chromogenic Candida agar and CHROMagar Candida in recovery and presumptive identification of monofungal and polyfungal vaginal isolates. Med Mycol 48:29-34. doi:10.3109/ 13693780802713224

Ponton J, Moragues MD, Quindos G (2002) Non-culture-based diagnostics. In: Calderone RA (ed) Candida and candidiasis. ASM Press, Washington, $\mathrm{DC}$

Schütte UM, Abdo Z, Bent SJ, Shyu C, Williams CJ, Pierson JD, Forney LJ (2008) Advances in the use of terminal restriction fragment length polymorphism (T-RFLP) analysis of 16S rRNA genes to characterize microbial communities. Appl Microbiol Biotechnol 80:365-380. doi:10.1007/s00253-008-1565-4

Silveira-Gomes F, Sarmento DN, Espírito-Santo EP, Souza NdeO, Pinto TM, Marques-da-Silva SH (2011) Differentiation between Candida albicans and Candida dubliniensis using hypertonic Sabouraud broth and tobacco agar. Rev Soc Bras Med Trop 44:457-460

Siqueira JF Jr, Sakamoto M, Rosado AS (2017) Microbial community profiling using terminal restriction fragment length polymorphism (T-RFLP) and denaturing gradient gel electrophoresis (DGGE). Methods Mol Biol 1537:139-152

Tortorano AM, Caspani L, Rigoni AL, Biraghi E, Sicignano A, Viviani MA (2004) Candidosis in the intensive care unit: a 20 -year survey. J Hosp Infect 57:8-13

Trtkova J, Raclavsky V (2006) Molecular-genetic approaches to identification and typing of pathogenic Candida yeasts. Biomed Pap Med Fac Univ Palacky Olomouc Czech Repub 150:51-61

Waldron LS, Ferrari BC, Gillings MR, Power ML (2009) Terminal restriction fragment length polymorphism for identification of Cryptosporidium species in human feces. Appl Environ Microbiol 75:108-112. doi:10.1128/AEM.01341-08

Zane L, Bargelloni L, Patarnello T (2002) Strategies for microsatellite isolation: a review. Mol Ecol 11:1-16

Zhang R, Thiyagarajan V, Qian PY (2008) Evaluation of terminalrestriction fragment length polymorphism analysis in contrasting marine environments. FEMS Microbiol Ecol 65:169-178. doi:10. $1111 / j .1574-6941.2008 .00493 . x$ 